Check for updates

Cite this: RSC Adv., 2018, 8, 38376

\title{
Bamboo leaf-based carbon dots for efficient tumor imaging and therapy $\dagger$
}

\author{
Mochamad Zakki Fahmi, (D) *a Abdul Haris, ${ }^{a}$ Ahmadi Jaya Permana, ${ }^{a}$ Denika Liyan Nor \\ Wibowo, ${ }^{a}$ Bambang Purwanto, ${ }^{b}$ Yatim Lailun Nikmah ${ }^{c}$ and Adi Idris ${ }^{d}$
}

In this study, carbon dots synthesized from bamboo leaf cellulose were used simultaneously as a staining agent and for doxorubicin delivery to target cancer cells. Owing to their nontoxic properties, the production of carbon dots from bamboo leaves is a green approach involving optimized application of bamboo tree waste. For multifunctional applications, the carbon dots were modified with 4carboxybenzylboronic acid and doxorubicin to improve target specificity and drug delivery to HeLa tumor cells. The resulting modified carbon dots were characterized using different analytical techniques, which showed that they were biocompatible, nontoxic, and highly stable over a wide range of $\mathrm{pH}$ values and at high ionic strengths. Furthermore, in vitro confocal microscopy studies demonstrated their blue fluorescence and cellular pathway for entering HeLa cells via folate receptor-mediated endocytosis. Cell viability data and flow cytometry results also confirmed the selective uptake of the carbon dots by HeLa cells, which significantly enhanced cell cytotoxicity.

Received 25th September 2018 Accepted 26th October 2018

DOI: $10.1039 / \mathrm{c} 8 \mathrm{ra07944g}$

rsc.li/rsc-advances properties, which are comparable to those of quantum dots, ${ }^{\mathbf{1 6}}$ and specific hydrophobic sites that allow simultaneously improved diagnostics and therapy. ${ }^{17}$ In the pursuit of synthetic methods for preparing carbon dots, using both bottom-up and top-down approaches, ${ }^{18}$ many carbon sources have been applied, including citric acid, ${ }^{9}$ carbohydrate and glucose, ${ }^{19,20}$ amino acid, ${ }^{21}$ grass, ${ }^{22}$ acetic acid, ${ }^{23}$ protein, ${ }^{24}$ egg, ${ }^{25}$ and fruit waste. ${ }^{26}$ The synthetic methods and reactants used have been found to influence the properties of the resulting carbon dots.

Despite extensive study, the development of effective and efficient methods for synthesizing carbon dots remains challenging. Investigations into using commercial or unused materials as carbon dot precursors have received interest owing to the potential advantages of the resulting carbon dots. Organic waste material can be considered an alternative material. There are many sources of natural organic materials, including plant leaves, among which waste bamboo leaves are produced in abundance and underutilized. Several reports have confirmed the antioxidant, ${ }^{27,28}$ antimicrobial, and antibacterial activities of bamboo leaves. ${ }^{29,30}$ Furthermore, the potential application of bamboo leaves as precursors of carbon dots used as the base material for copper ion detection has been reported. ${ }^{31}$ However, the application of carbon dots from waste bamboo leaves in both tumor detection and therapy has yet to be reported.

Using nanomaterials for tumor labelling and therapy has been proposed to overcome the problems of complicated syntheses, expensive precursors, and emission losses, which are the major factors preventing the specific targeting of tumor cells instead of normal cells. In this study, improvements in the synthesis of carbon dots from waste bamboo leaves and their 
modification to obtain specific targeting of HeLa tumor cells are reported. The abundance of folate receptors overexpressed on the surface of HeLa tumor cells motivated our selection of targeting agent CBBA (4-carboxybenzylboronic acid) for attachment to the synthesized carbon dots. Furthermore, tumor drug doxorubicin was attached to carbon dots to afford a drug delivery ability. In addition to characterization, stability, toxicity, and in vitro assays of HeLa tumor cells taken up on this material were performed to confirm that these multifunctional carbon dots can be used for tumor detection and therapy.

\section{Experimental section}

\section{Materials}

Bamboo leaves from Gigantochloa apus were collected near Airlangga University, Indonesia. Sodium hydroxide, sodium hypochlorite (NaOCl), $N$-(3-dimethylaminopropyl)- $N{ }^{\prime}$-ethylcarbodiimide hydrochloride (EDCI, 97\%), 3-(4,5-dimethylthiazol-2-yl)-2,5diphenyltetrazolium bromide (MTT, 97.5\%), 4-dimethylaminopyridine (DMAP, 98\%), doxorubicin (Dox, 98\%), and 4-carboxybenzylboronic acid (CBBA, 98\%) were purchased from Sigma Aldrich (Milwaukee, WI, USA). Citric acid was purchased from Bratachem Co. Ltd. (Jakarta, Indonesia). All chemicals were used directly without further purification.

\section{Synthesis of carbon dots}

Bamboo leaves, as the carbon dot (CD) precursor, were first cleaned and dried at $120{ }^{\circ} \mathrm{C}$ for $2 \mathrm{~h}$. The dried leaves were sliced to give $2 \mathrm{~kg}$ of sliced leaves and then refluxed with $1 \mathrm{M} \mathrm{NaOH}(10$ $\mathrm{mL}$ ) at $60{ }^{\circ} \mathrm{C}$ for $4 \mathrm{~h}$. After rinsing with DI water, the leaves were further immersed in $\mathrm{NaOCl}$ solution $(10 \mathrm{~mL}, 5 \%(\mathrm{v} / \mathrm{v}))$ for bleaching. The obtained cellulose was precipitated by centrifugation at $2000 \mathrm{rpm}$ for $15 \mathrm{~min}$ and pyrolyzed at $250{ }^{\circ} \mathrm{C}$ for $30 \mathrm{~min}$ in a furnace. The resulting CDs stacked at the reactor wall were dissolved in $0.5 \mathrm{M} \mathrm{NaOH}$ and filtered through a syringe $(0.22 \mu \mathrm{m})$ to remove larger particles. The CDs were then dialyzed using a cellulose dialysis bag (MWCO, $1000 \mathrm{Da}$ ) for $24 \mathrm{~h}$ to separate smaller particles and unreacted reagent. The obtained CDs were used in the next step.

\section{Attaching CBBA to CD(CBBA-CD) and Dox loading}

The attachment of CBBA onto CDs was achieved using the DMAP/EDCI mechanism. CBBA (13.3 mg) was dissolved in DI water $(10 \mathrm{~mL})$ and EDCI $(23.7 \mathrm{mg})$ was added under stirring to afford a homogenous solution. Meanwhile, to a solution of CDs ( $5 \mathrm{~mL}, 0.5 \mathrm{mg} \mathrm{mL}^{-1}$ ) was added DMAP, followed by treatment using an ultrasonic probe (JY-9211DN, Ningbo Scientz Biotechnology, Co. Ltd., China) operated at $20 \mathrm{~Hz}$ and $130 \mathrm{~W}$ power for $2 \mathrm{~min}$ to accelerate DMAP dissolution. The two solutions were mixed at pH 6 using a magnetic stirrer for $24 \mathrm{~h}$. The resulting mixture was then dialyzed using a cellulose membrane (MWCO, $1000 \mathrm{Da}$ ) for $24 \mathrm{~h}$ to remove unreacted substrates and byproducts. This dialyzed solution was used for further experiments.

Tumor drug Dox was loaded onto CBBA-CDs by adding Dox (about $5 \mathrm{mg}$ ) to CBBA-CD solution $(15 \mathrm{~mL}$ ) with stirring for $24 \mathrm{~h}$.
Unconjugated Dox was separated from Dox-loaded CBBA-CDs (Dox/CBBA-CDs) by dialysis for $24 \mathrm{~h}$ using similar conditions to the previous dialysis process. The amount of Dox stacked on CBBA-CD was further assessed by its absorption at $482 \mathrm{~nm}$ compared with the standard concentration. The loading efficiency and loading amount were measured using eqn (1) and (2).

$$
\begin{aligned}
& \text { Percentage of loading efficiency }(\%) \\
& \qquad=\frac{\text { mass of Dox on CBBA-CD }}{\text { mass of Dox in feed }} \times 100
\end{aligned}
$$

Percentage of loading amount $(\%)$

$$
=\frac{\text { mass of Dox on CBBA-CD }}{\text { mass of CBBA-CD }} \times 100
$$

\section{Dox release pattern}

The pattern of Dox release was assessed by dialyzing Dox/CBBACDs using a cellulose membrane (MWCO, 1000 Da) immersed in an outer PBS aqueous solution. Aliquots (about $1 \mathrm{~mL}$ ) of the PBS solution were removed at certain times, while the volume of the PBS buffer was kept at $50 \mathrm{~mL}$. The Dox concentration released into the outer solution was measured by tracking Dox absorbance and corrected using eqn (3):

$$
C t^{\prime}=C t+\frac{v}{V} \sum_{0}^{i-t} C t
$$

where $C t^{\prime}$ is the corrected concentration at time $t, C t$ is the apparent concentration at time $t, v$ is the volume of aliquots taken, and $V$ is the total buffer volume. The effect of $\mathrm{pH}$ on Dox release was investigated by adjusting the $\mathrm{pH}$ value of the outer solution to $5.0,7.4$, and 9.0.

\section{Cell culture}

For culturing human cervical (HeLa) tumor cells, Eagle's minimum essential medium (containing $1.5 \mathrm{~g} \mathrm{~L}^{-1}$ sodium bicarbonate) supplemented with $1 \%$ L-glutamine, $1 \%$ antibiotic antimycotic formulation, $1 \%$ non-essential amino acid, 1\% sodium pyruvate, and $10 \%$ fetal bovine serum was used as medium. The cells were then stored in a humidified $5 \% \mathrm{CO}_{2}$ incubator maintained at $37^{\circ} \mathrm{C}$.

\section{Cytotoxicity assessment}

Cell viability was quantified using an MTT assay in HeLa tumor cells. HeLa cells previously cultured in Eagle's minimum essential medium, as described above, were placed in 12-well plate (25000 cells per well) for $24 \mathrm{~h}$. After washing with phosphatebuffered saline (PBS, UniRegion Biotech, Taiwan), the proliferated cells were further washed with PBS and incubated with adjusted samples for $24 \mathrm{~h}$. After washing the plate twice with PBS, MTT reagent $\left(1 \mathrm{~mL}, 500 \mathrm{mg} \mathrm{mL}^{-1}\right)$ was added and incubated for 
$4 \mathrm{~h}$. To dissolve formazan crystals, dimethyl sulfoxide $(1 \mathrm{~mL})$ was added to each well and the absorbance of the crystals was measured at $570 \mathrm{~nm}$ using an Elisa reader (Biotech Powerwave XS). The absorbance intensity was related to the amount of formazan and was proportional to the number of live cells.

\section{Confocal imaging observation}

The HeLa cells were first seeded in a 6-well plate in culturing medium $(2 \mathrm{~mL})$ and cultured for $24 \mathrm{~h}$. After incubating with sample $(300 \mu \mathrm{L})$ for $60 \mathrm{~min}$, the cells were washed three times with PBS solution and then fixed with $70 \%$ alcohol for $10 \mathrm{~min}$. Fluorescence images of HeLa cells were acquired using a Leica TCS SP2 inverted confocal microscope (Leica Microsystems) equipped with a $63 \times 1.32$ NA oil immersion objective. Confocal images were obtained by illuminating the samples with inline $\operatorname{Ar}(488 \mathrm{~nm})$ and He-Ne (503-680 nm and $588 \mathrm{~nm})$ lasers.

\section{Flow cytometry analysis}

Approx. $3 \times 10^{5}$ cells were individually cultured in a cell flask with medium $(5 \mathrm{~mL}$ ) for $24 \mathrm{~h}$. The medium was then replaced with fresh medium ( $5 \mathrm{~mL}$ ) containing different concentrations of samples, with PBS-treated cells used as control. After incubating for $1 \mathrm{~h}$, the treated cells were rinsed with PBS, trypsinized, centrifuged, and suspended in binding buffer. The cells were then stained with Annexin V-FITC (5 $\mu \mathrm{L})$ for $15 \mathrm{~min}$, washed with binding buffer, and stained with propidium iodide $(10 \mu \mathrm{L})$. The samples were analyzed on a Guava easyCyte Flow Cytometer equipped with an argon laser (488 nm).

\section{Characterization}

High resolution-transmission electron microscopy (HR-TEM) images were obtained on a Philips Tecnai G2 F20 microscope (Philips, Holland) and assigned using energy-dispersive X-ray spectroscopy (EDS) at $200 \mathrm{kV}$. Powder X-ray diffraction (XRD) patterns were obtained using a Rigaku $18 \mathrm{~kW}$ rotating anode source X-ray diffractometer with $\mathrm{Cu} \mathrm{K}_{\alpha 1}$ line radiation $(\lambda=1.54$ $\AA$ ). UV-Vis absorption spectra were measured using a JASCO V670 spectrometer. PL spectra were measured using a PerkinElmer LS 55 spectrofluorometer equipped with a $20 \mathrm{~kW}$ xenon lamp. Atomic force microscopy ${ }^{\mathbf{1 2}}$ images were acquired using a scanning probe AFM5500M instrument (Hitachi Co., Japan) at ambient temperature. Raman analysis was performed using a MRS-320 Raman Instrument system (Horiba Ltd., Japan).

\section{Statistical analysis}

Statistical analysis, including the cytotoxic concentration causing a $50 \%$ decrease in cell viability $\left(\mathrm{CC}_{50}\right)$, was performed using dose-response mode on the nonlinear fitting curve in Origin software (version 8.0724, OriginLab Inc., Northampton, MA). All data were obtained in triplicate, and means were compared using a paired-sample $t$-test.

\section{Results and discussion}

\section{CD preparation}

CDs were synthesized by pyrolyzing cellulose in bamboo leaves, as shown in Scheme 1. Several treatments, including the addition $\mathrm{NaOH}$ and $\mathrm{NaOCl}$ solutions, were performed to collect cellulose from lignin and bleach the collected cellulose, respectively. Extraction was conducted for $2 \mathrm{~h}$ until the $\mathrm{NaOH}$ changed color to black and the bamboo leaf color faded. The extraction process aimed to degrade lignin in bamboo leaves, because lignin compounds can interfere with the synthesis of carbon dots obtained as the result of the pyrolysis of cellulose in bamboo leaves. The collected cellulose was then heated to $250{ }^{\circ} \mathrm{C}$. This process allowed carbonation of cellulose, which both reconstructed and combined the polysaccharides, resulting in a graphene oxide structure. As shown in previous studies, incomplete carbonation will drive cellulose to form CDs. ${ }^{31,32}$

CD formation was first confirmed by XRD. The crystallinity of the CDs was confirmed by a certain peak observed in the $2 \theta$ range diffractogram $20-25^{\circ}$. The XRD results for CDs synthesized at $300{ }^{\circ} \mathrm{C}$ are shown in Fig. 1 . The signal of crystalline CDs

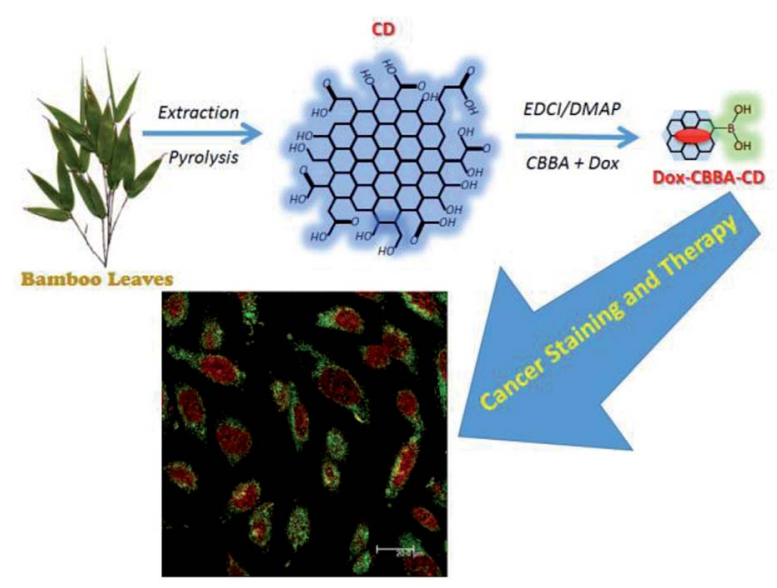

Scheme 1 Synthesis and modification of bamboo leaf-based carbon dots.

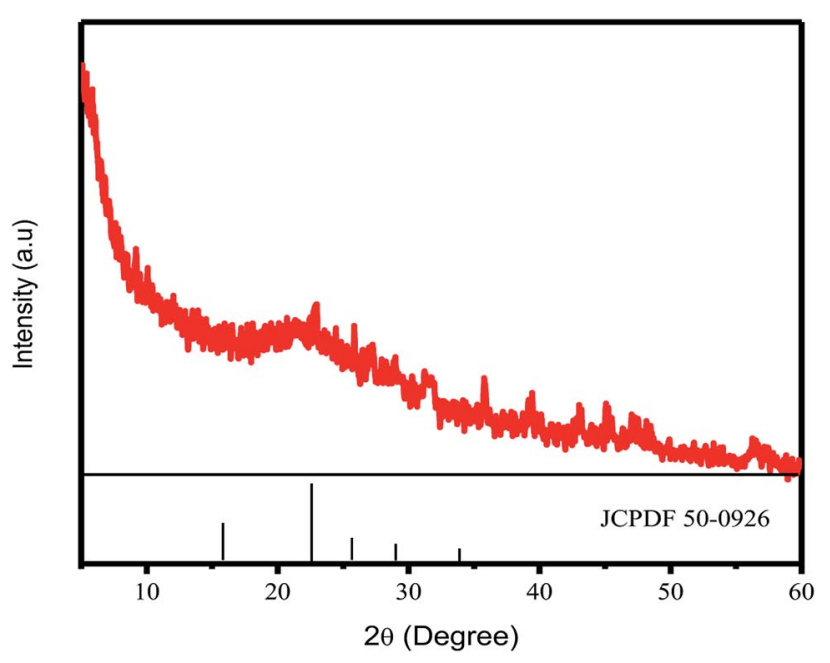

Fig. 1 XRD pattern of CDs. 
was observed at $22.7^{\circ}$ Prasannan et al. reported that crystalline CDs were observed at a $2 \theta$ value of $22.7^{\circ} \cdot{ }^{26}$ The XRD results also indicated the size of the crystalline CDs, with the $2 \theta$ position at $22.7^{\circ}$ corresponding to an FWHM value of about 604 948, which was converted to a carbon nanoparticle size of about $0.24 \mathrm{~nm}$ using the Scherrer equation.

Furthermore, optical analysis of the prepared CDs by UV-Vis spectrophotometry (Fig. 2a) showed a shoulder peak at $360 \mathrm{~nm}$, attributed to the particular exciton of CDs. As supported by our previous report, this indicated CD formation in the carbonation process. ${ }^{9}$ CD luminescence was characterized by PL spectroscopy (Fig. 2a). By varying the temperature of pyrolysis, the CD emissions showed insignificant luminescence emission at wavelengths of around 425-475 $\mathrm{nm}$. These differences showed the graphene-like structure of CDs prepared from the carbonization of bamboo leaves. The difference in the maximum emission peak was around $5 \mathrm{~nm}$. Zhu et al. reported that CD emission in the range 425-475 $\mathrm{nm}$ confirmed a CD size of below $5 \mathrm{~nm}$, which emitted blue luminescence. ${ }^{33}$

The AFM results (Fig. 2b) indicated that the size of CDs from bamboo leaves averaged $2 \mathrm{~nm}$, with some CDs having sizes of over $4 \mathrm{~nm}$. High-magnification HR-TEM (Fig. 2c) systematically showed the carbon structures, confirming the formation of a graphene-like structure in the CDs. Furthermore, Raman spectra (Fig. 2d) showed the G-band peak of CDs at $1582 \mathrm{~cm}^{-1}$ and a D-band peak at $1332 \mathrm{~cm}^{-1}$, attributed to the vibration of $\mathrm{sp}^{2}$-hybridized and $\mathrm{sp}^{3}$-hybridized carbon atoms at the edge of the crystal, respectively. This peak supported that the CDs formed a graphene-like crystal structure. Furthermore, a higher D-band intensity supported the formation of more amorphous phase at the terminal end of the carbon plane, which was responsible for the water solubility of the CDs rather than the CD emission.

\section{Conjugation of CBBA onto CDs (CBBA-CDs)}

CDs were modified with CBBA to afford CD that specifically target tumor cells. Previous research has shown that boronic acids have a high affinity for cis-diol moieties in sialic acid, which generally exists on the membrane of tumor cells. ${ }^{34}$ Therefore, CBBA can specifically guide CDs to tumor cells. However, the addition of CBBA to the CDs required a specific catalyst, namely the Steglich catalyst. This catalyst was used for esterification between carboxylic acid groups in CBBA and alcohol groups in the CDs. The mechanism of the Steglich reaction is shown in Fig. $\mathrm{S} 1$ (ESI $\dagger$ ). In this esterification reaction, EDCI acts as a cross-linker, making the reaction irreversible. To evaluate the change in CD size before and after CBBA modification, AFM images of CBBA-CDs and their size distributions were measured, as shown in Fig. S2 (ESI $\dagger$ ). The histogram data showed an insignificant increase in the size distribution of CBBA-CDs, with average sizes of about $2.5 \mathrm{~nm}$.
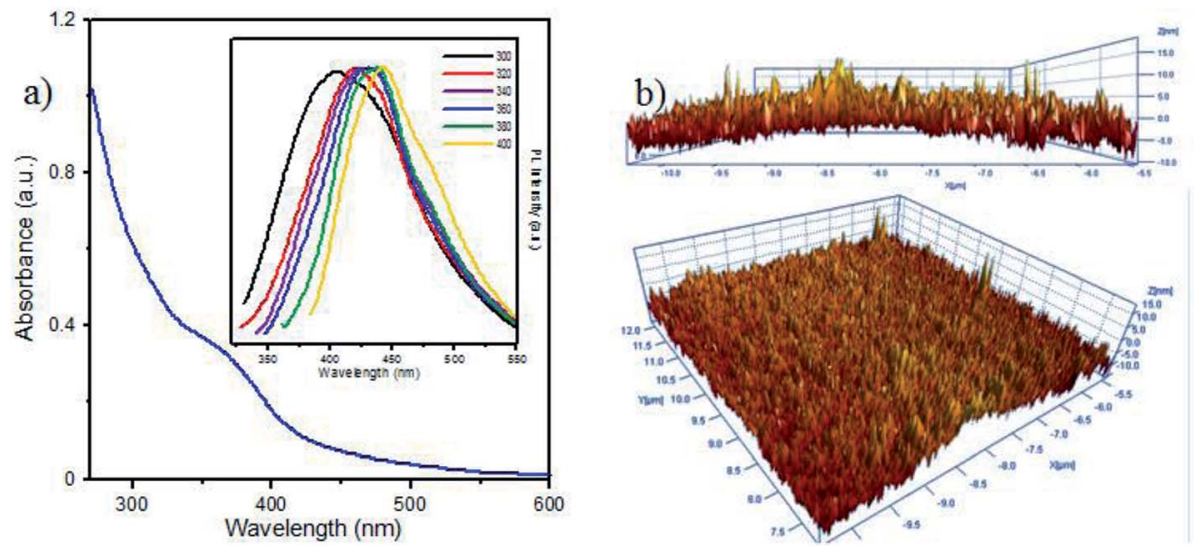

c)

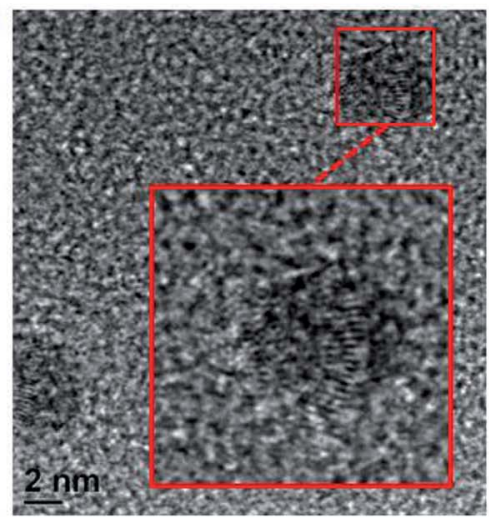

d)

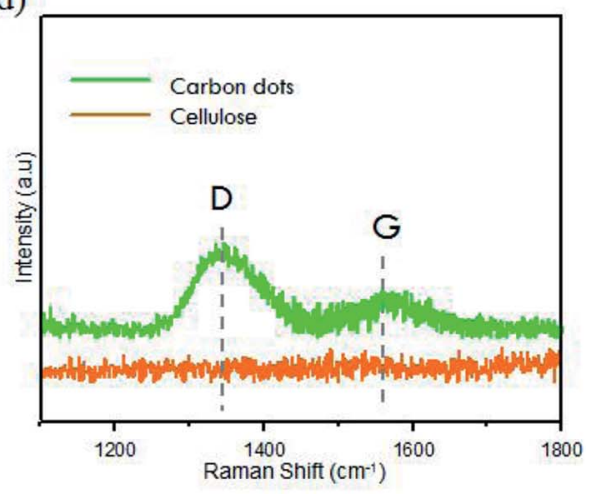

Fig. 2 (a) UV-Vis spectra of CDs. Inset: PL spectra at varied temperatures, namely $200{ }^{\circ} \mathrm{C}$ (red), $250{ }^{\circ} \mathrm{C}$ (green), $300{ }^{\circ} \mathrm{C}$ (blue), $350{ }^{\circ} \mathrm{C}$ (pink), $400{ }^{\circ} \mathrm{C}$ (brown). (b) AFM images of CDs in vertical and diagonal views. (c) HR-TEM images of CDs with high magnification image on adjusted square. (d) Raman spectra of CDs and raw cellulose. Inset: Photograph of CDs compared with water under UV lamp (365 nm). 
This showed that modification with CBBA maintained the original CD size.

FTIR was also used to assess the presence of CBBA on the CDs (Fig. 3). For CBBA-CDs, boron dihydroxy (O-B-O) bond vibrations were observed at $1266 \mathrm{~cm}^{-1}$ (asymmetric stretching), $1215 \mathrm{~cm}^{-1}$ (deformation), and $507 \mathrm{~cm}^{-1}$ (bending vibration), along with a B-O-H stretching band at $1083 \mathrm{~cm}^{-1} \cdot{ }^{35}$ Other bands at 745 and $670 \mathrm{~cm}^{-1}$ were attributed to bending vibrations of B-O-H. ${ }^{36}$ Furthermore, pristine CDs also showed bands at 713,874 , and $1083 \mathrm{~cm}^{-1}$, which were attributed to vibrations of $\mathrm{C}-\mathrm{H}$ aromatic groups.

\section{Loading of Dox onto CBBA-CDs (Dox/CBBA-CDs)}

As-prepared CBBA-CDs were physically conjugated with tumor cell drug Doxorubicin (Dox) using the procedure described in Scheme 1 to determine the Dox delivery ability of the CDs. In this procedure, Dox was loaded onto CBBA-CDs through electrostatic interactions. As reported previously, Dox can stack on graphene-like structures through $\pi-\pi$ interactions among benzene structures. ${ }^{5}$ Therefore, DOX exhibited a high affinity for negatively charged BSA (isoelectric point, $\mathrm{pH}=5.4$ ).

To investigate the Dox delivery potential of the CDs, we evaluated the cellular uptake of CDs on HeLa tumor cells using confocal laser scanning microscopy (CLSM). CLSM is a powerful method for observing the internalization of CDs, CBBA-CDs, and Dox/CBBA-CDs into HeLa tumor cells (Fig. 4). Significant green fluorescence was observed from CBBA-CDs on the cytoplasm of HeLa tumor cells after $1 \mathrm{~h}$ of incubation. Compared with CDs, which did not show green emission (Fig. 4a), the existence of green fluorescence confirmed that CDs were readily taken up by the cells via endocytosis (Fig. 4b). These findings also showed that boronic acids were good targeting agents for CDs onto tumor cells. Furthermore, Dox delivery was successfully achieved using CBBA-CDs, with red fluorescence, the characteristic emission of Dox, observed in the nuclei of cells treated with Dox/CBBA-CDs. Dox operates as a tumor drug by disturbing the DNA helix structure in the cell nucleus.
Therefore, the appearance of red fluorescence in the cell nucleus after incubation with Dox confirmed that the drug had been successfully delivered to the target.

Cytotoxicity assessment of CDs was conducted using an MTT assay. After incubation for $24 \mathrm{~h}$, the MTT results (Fig. 5) showed excellent cell viability (over $80 \%$ ) for both CDs and CBBA-CDs. This strongly suggested that CDs and CBBA-CDs had low toxicity, even when the CD concentration was increased to 400 $\mu \mathrm{g} \mathrm{mL}{ }^{-1}$. However, toxicity was observed after loading Dox onto the CDs (Dox/CBBA-CDs). Starting at a low concentration $(10 \mu \mathrm{g}$ $\mathrm{mL}^{-1}$ ), Dox decreased the cell viability. Furthermore, halfmaximal inhibitory concentration $\left(\mathrm{IC}_{50}\right)$ values were determined using dose-response graphs obtained after treating HeLa cells with free Dox and Dox/CBBA-CDs (Fig. S3, ESI $\dagger$ ). Analysis showed that free Dox resulted in lower $\mathrm{IC}_{50}$ values (52.3 $\mathrm{mg} \mathrm{mL}^{-1}$ ) than Dox/CBBA-CDs $\left(68.2 \mathrm{mg} \mathrm{mL}^{-1}\right)$. This suggested that CBBA-CDs successfully achieved delivery of Dox to the target cells.

Further in vitro assessments of the obtained CDs were directed toward measuring the characteristic emission on HeLa cells via flow cytometry analysis. This method can detect the fluorescence of materials accumulated on microorganisms, such as HeLa cells. The graph in Fig. 6 shows the intensity of green fluorescence in cells treated with CDs and CBBA-CDs after incubation for $1 \mathrm{~h}$. Compared with untreated cells and CD-treated cells as control, the fluorescence of cells treated with CBBA-CDs was significantly higher. These data were supported by the previous CLSM results, which indicated that CBBA worked well to deliver CDs specifically to HeLa cells. The formation of tetravalent complexes between the boronic acid sites and cis-diols in sialic acid on the outer cell membrane was key to the insertion of CDs into the cell cytoplasm. Further flow cytometry analysis was focused on improving the cytotoxicity of CDs by assessing the number of apoptotic cells affected by CDs (Fig. 7a-d). In this study, Annexin V-FITC and propidium iodide were used as the kit package for detecting apoptosis and necrosis, respectively.

Annexin has a high affinity for phosphatidylserine expressed on the outer membrane once cell apoptosis has occurred and

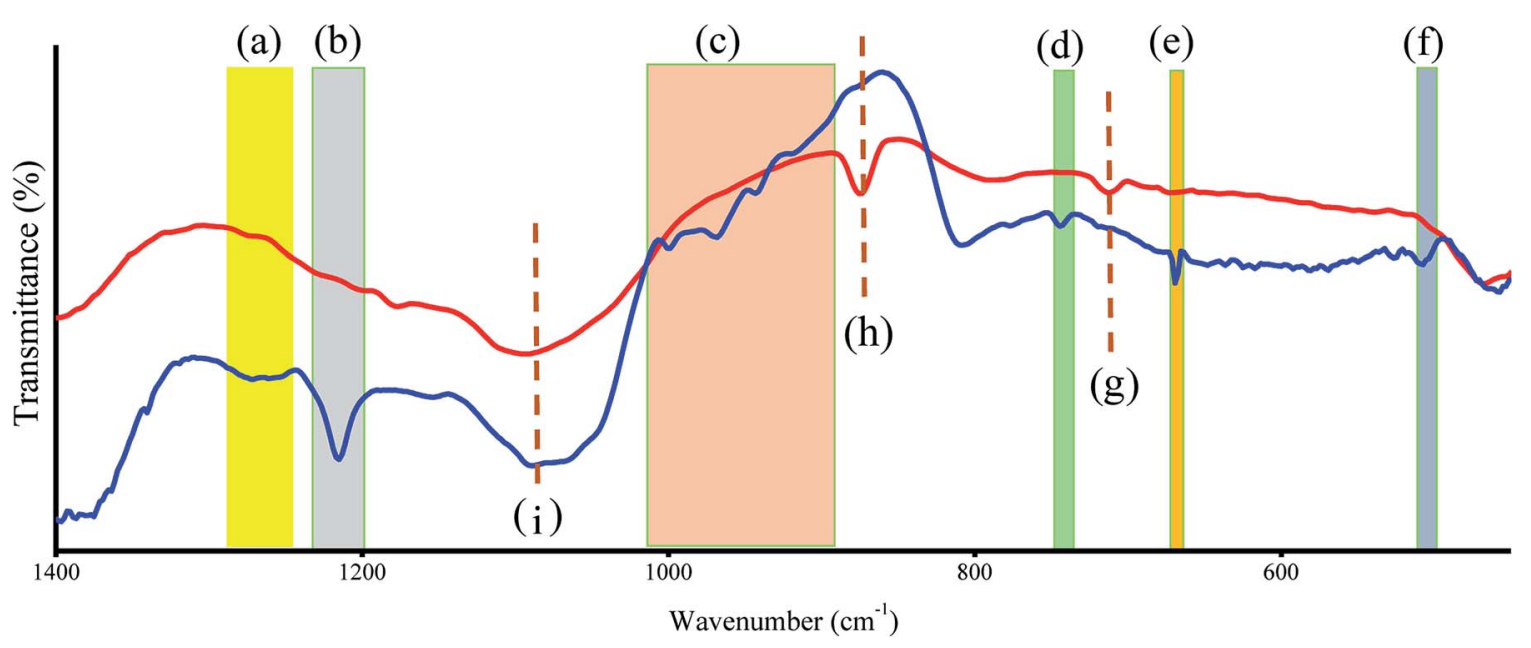

Fig. 3 FTIR spectra of CD (red line) and CBBA-CD (blue line). (a) to (f) refer to existence of CBBA site and (g) to (i) refer to CD vibration. 

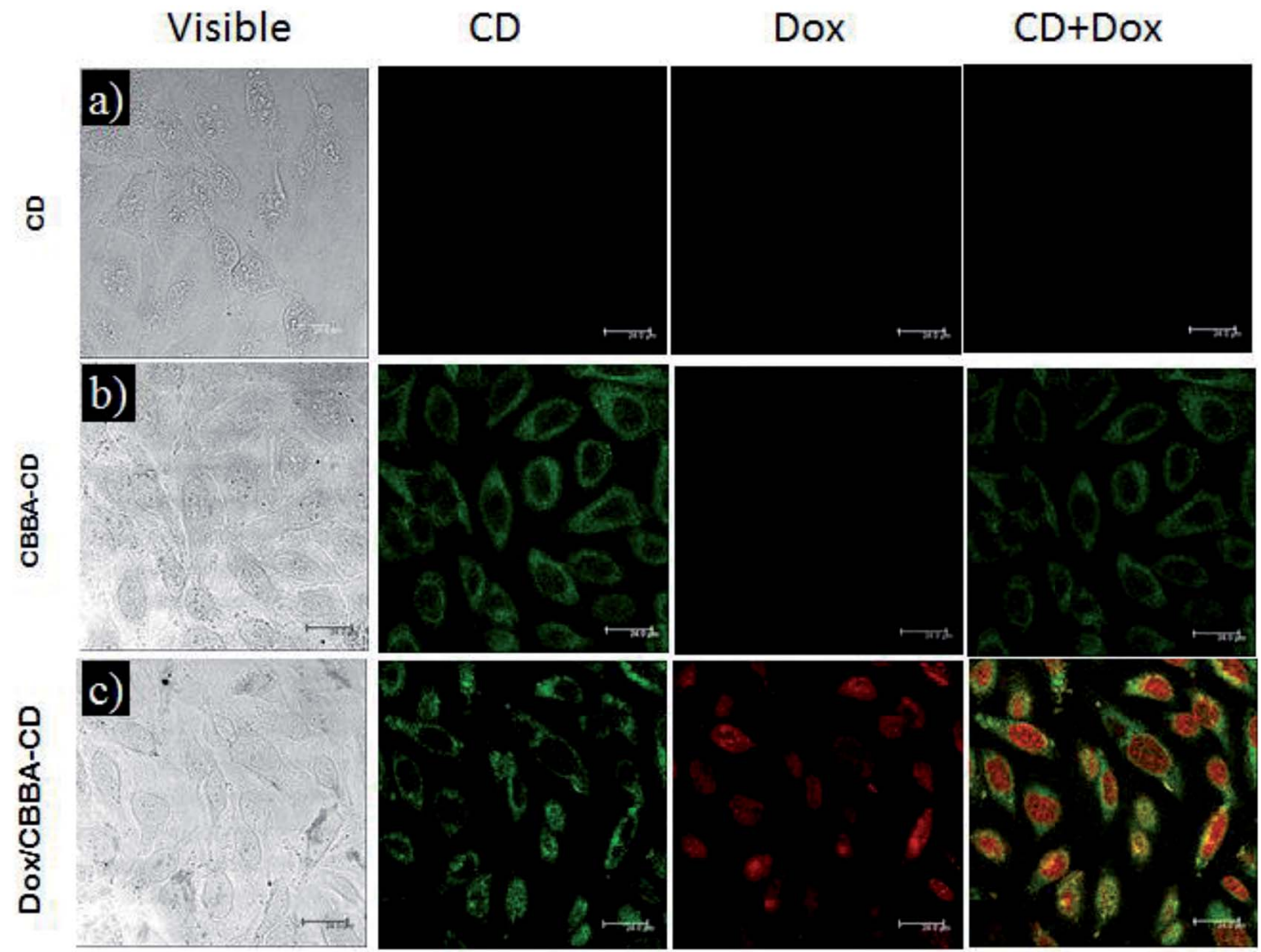

Fig. 4 CLSM images of (a) CDs, (b) CBBA-CDs, and (c) Dox/CBBA-CDs after incubation for $1 \mathrm{~h}$ with HeLa cells at $37^{\circ} \mathrm{C}$. Scale bars represent 24 $\mu \mathrm{m}$.

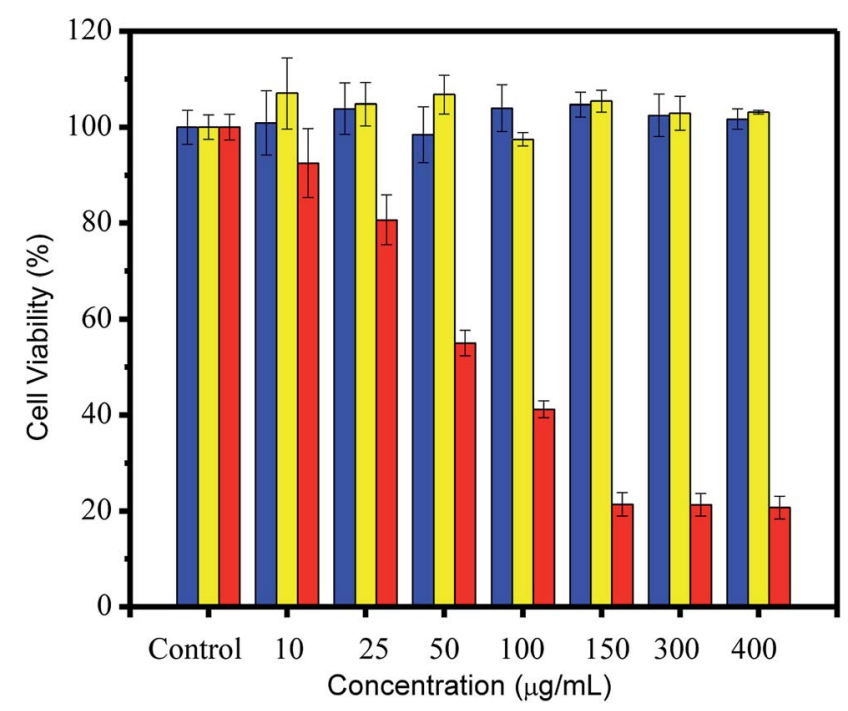

Fig. 5 Cell viability study through MTT assay of HeLa cells after $24 \mathrm{~h}$ of treatment with CDs (blue), CBBA-CDs (yellow), and Dox/CBBA-CDs (red). All MTT data are shown as means \pm SD $(n=3)$.

green fluorescence emerging from connected FITC. In contrast, propidium iodide, which shows red fluorescence, conjugates to cell DNA during necrosis. The flow cytometry quadrant data of untreated cells (Fig. 7a) was established as the control, in which

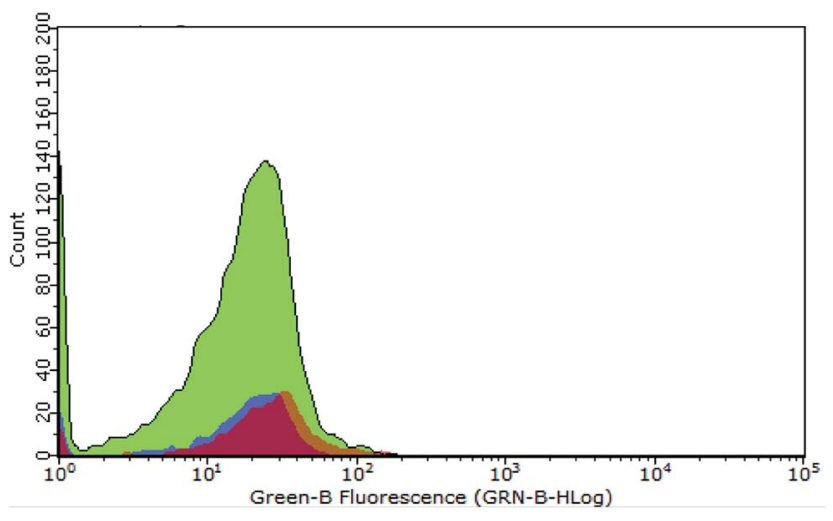

Fig. 6 Flow cytometry data representing fluorescence distribution of untreated cells (purple area), CD-treated cells (orange area), and CBBA-CD-treated cells (green area).

all cells existed in quadrant 1 (Annexin, negative; PI, negative). The addition of CDs onto cell did not have a toxic effect upon living cells, while the absence of CDs on the cell cytoplasm resulted in the cell performing like the control cells or untreated cells; therefore, almost all cells were in quadrant 1 (Fig. 7b). Furthermore, the presence of CBBA on CDs resulted in some cells $(23.5 \%)$ undergoing necrosis in quadrant 3 (Annexin, negative; PI, positive), which is a form of uncontrolled or pathological death cell and cannot be claimed as proof of CD 
a)

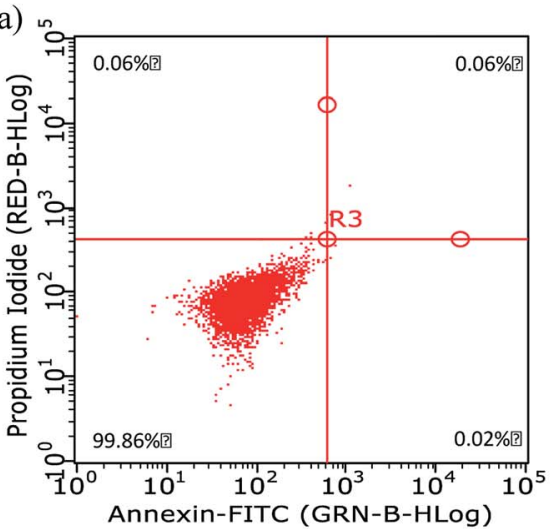

c)

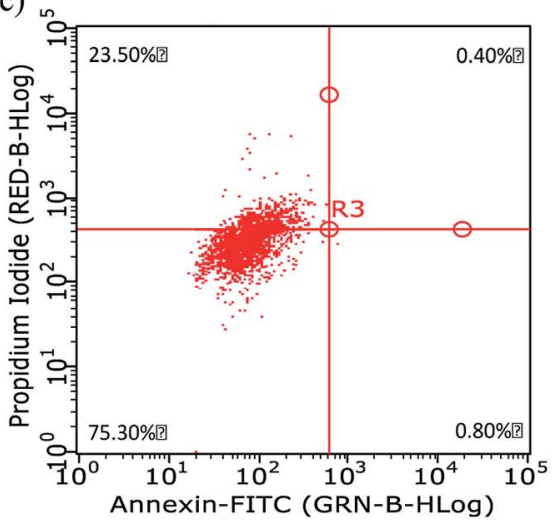

b)

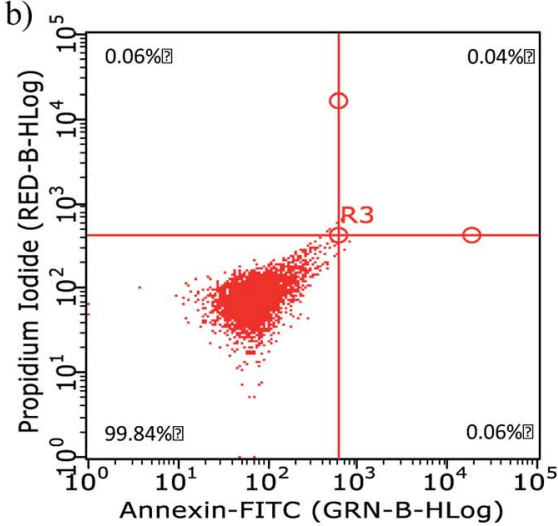

d)

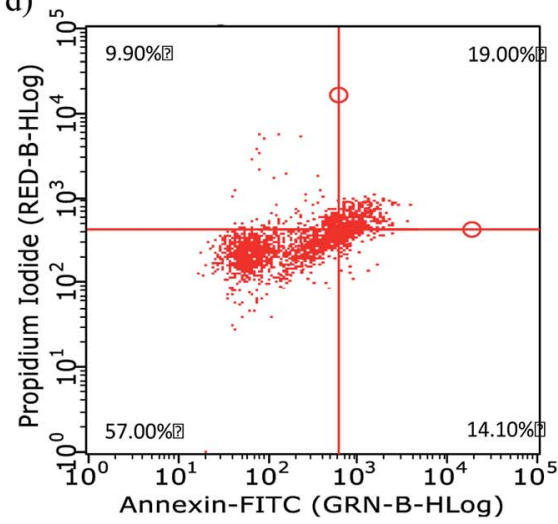

Fig. 7 Apoptosis data of HeLa cells (a) before and (b-d) after $1 \mathrm{~h}$ of incubation with (b) CDs, (c) CBBA-CDs, and (d) Dox/CBBA-CDs.

toxicity (Fig. 7c). In contrast, cells treated with Dox/CBBA-CDs showed $14.1 \%$ early apoptosis (Annexin, positive; PI, negative) and 19\% late apoptosis (Annexin, positive; PI, positive). Apoptosis is a programmed form of cell death, caused in this case by Dox damaging DNA formation in the cell (Fig. 7d). This findings demonstrated that CBBA-CDs and Dox can successfully deliver drugs and kill the targeted cell, respectively.

\section{Conclusions}

We have demonstrated the application of cellulose from bamboo leaves as a raw material for the synthesis of CDs for imaging and drug delivery. The resulting CDs were nontoxic, biocompatible, and exhibited a graphene-like structure that accommodated tumor drug Dox. This method was used to construct multifunctional nanoparticle for imaging and drug delivery by conjugation of CBBA and Dox onto the CDs, respectively. CBBA acts as a targeting agent and stabilizes the CDs. An efficient method for preparing CDs valuable against tumor cells was achieved by conjugation with Dox. Cytotoxicity investigations via MTT and flow cytometry showed the toxic effects of this type of nanomaterial after binding with Dox. The design of modified CDs can hopefully motivate the future development of novel approaches for preparing multi-purpose nanomaterials.

\section{Conflicts of interest}

There are no conflicts to declare.

\section{Acknowledgements}

The authors thank the Ministry of Research and Technology, Republic of Indonesia, for full support of this study, and the SATU Joint Research Program and Universitas Airlangga for providing research facilities.

\section{Notes and references}

1 C. Lherm, R. H. Müller, F. Puisieux and P. Couvreur, Int. J. Pharm., 1992, 84, 13-22.

2 J. S. Tsuji, A. D. Maynard, P. C. Howard, J. T. James, C.-w. Lam, D. B. Warheit and A. B. Santamaria, Toxicol. Sci., 2006, 89, 42-50.

3 N. Savage and M. S. Diallo, J. Nanopart. Res., 2005, 7, 331342.

4 C. Andreou, V. Neuschmelting, D.-F. Tschaharganeh, C.-H. Huang, A. Oseledchyk, P. Iacono, H. Karabeber, R. R. Colen, L. Mannelli and S. W. Lowe, ACS Nano, 2016, 10, 5015-5026.

5 M. Z. Fahmi, K.-L. Ou, J.-K. Chen, M.-H. Ho, S.-H. Tzing and J.-Y. Chang, RSC Adv., 2014, 4, 32762-32772. 
6 W. M. Girma, M. Z. Fahmi, A. Permadi, M. A. Abate and J.-Y. Chang, J. Mater. Chem. B, 2017, 5, 6193-6216.

7 H. J. Park, E. J. Jeon, J. S. Lee, S. H. Hong, A. N. Cho, J. Lee, J. S. Moon, K. E. Jung, J. W. Oh and H. Lee, Advanced Healthcare Materials, 2016.

8 G. Ortega, J. Zuaznabar-Gardona, O. Morales-Tarré and E. Reguera, RSC Adv., 2016, 6, 98457-98465.

9 M. Z. Fahmi, W. Sukmayani, S. Q. khairunisa, a. m. witaningrum, d. w. indriati, m. q. y. matondang, J.-Y. Chang, T. Kotaki and M. Kameoka, $R S C$ Adv., 6(95), 92996-93002.

10 Y. H. Lim, K. M. Tiemann, D. A. Hunstad, M. Elsabahy and K. L. Wooley, Wiley Interdisciplinary Reviews: Nanomedicine and Nanobiotechnology, 2016.

11 M. Latha, M. Priyanka, P. Rajasekar, R. Manikandan and N. Prabhu, Microb. Pathog., 2016, 93, 88-94.

12 H. A. Hassan, L. Smyth, J. T.-W. Wang, P. M. Costa, K. Ratnasothy, S. S. Diebold, G. Lombardi and K. T. AlJamal, Biomaterials, 2016, 104, 310-322.

13 Y. Zhang, Z. Cui, H. Kong, K. Xia, L. Pan, J. Li, Y. Sun, J. Shi, L. Wang and Y. Zhu, Adv. Mater., 2016, 28(14), 2699-2708.

14 D. Naskar, P. Bhattacharjee, A. K. Ghosh, M. Mandal and S. C. Kundu, ACS Appl. Mater. Interfaces, 2016, 9(23), 19356-19370.

15 T. Feng, X. Ai, G. An, P. Yang and Y. Zhao, ACS Nano, 2016, 10(4), 4410-4420.

16 L. Cao, S.-T. Yang, X. Wang, P. G. Luo, J.-H. Liu, S. Sahu, Y. Liu and Y.-P. Sun, Theranostics, 2012, 2, 295-301.

17 S. Y. Choi, S. H. Baek, S.-J. Chang, Y. Song, R. Rafique, K. T. Lee and T. J. Park, Biosens. Bioelectron., 2017, 93, 267273.

18 J. C. E. da Silva and H. M. Gonçalves, TrAC, Trends Anal. Chem., 2011, 30, 1327-1336.

19 S. K. Bhunia, A. Saha, A. R. Maity, S. C. Ray and N. R. Jana, Sci. Rep., 2013, 3, 1473.
20 H. Peng, Y. Li, C. Jiang, C. Luo, R. Qi, R. Huang, C.-G. Duan and J. Travas-Sejdic, Carbon, 2016, 100, 386-394.

21 J. Jiang, Y. He, S. Li and H. Cui, Chem. Commun., 2012, 48, 9634-9636.

22 S. Liu, J. Tian, L. Wang, Y. Zhang, X. Qin, Y. Luo, A. M. Asiri, A. O. Al-Youbi and X. Sun, Adv. Mater., 2012, 24, 2037-2041.

23 Y. Fang, S. Guo, D. Li, C. Zhu, W. Ren, S. Dong and E. Wang, ACS Nano, 2011, 6, 400-409.

24 Z. Zhang, J. Hao, J. Zhang, B. Zhang and J. Tang, RSC Adv., 2012, 2, 8599-8601.

25 J. Wang, C. F. Wang and S. Chen, Angew. Chem., 2012, 124, 9431-9435.

26 A. Prasannan and T. Imae, Ind. Eng. Chem. Res., 2013, 52, 15673-15678.

27 X. Ma, E. Wang, Y. Lu, Y. Wang, S. Ou and R. Yan, PLoS One, 2015, 10, e0130680.

28 B. Lu, X. Wu, X. Tie, Y. Zhang and Y. Zhang, Food Chem. Toxicol., 2005, 43, 783-792.

29 D.-K. Chung and R.-N. Yu, Korean J. Food Sci. Technol., 1995, 27, 1035-1038.

30 M. Kim, M. Byun and M. Jang, J. Korean Soc. Food Nutr., 1996, 25(1), 135-142.

31 Y. Liu, Y. Zhao and Y. Zhang, Sens. Actuators, B, 2014, 196, 647-652.

32 P. Shen, J. Gao, J. Cong, Z. Liu, C. Li and J. Yao, ChemistrySelect, 2016, 1, 1314-1317.

33 S. Zhu, Y. Song, X. Zhao, J. Shao, J. Zhang and B. Yang, Nano Res., 2015, 8, 355-381.

34 L. Liang and Z. Liu, Chem. Commun., 2011, 47, 2255-2257.

35 D. Buc, I. Bello, M. Caplovicova, M. Mikula, J. Kovac, I. Hotovy, Y. M. Chong and G. G. Siu, Thin Solid Films, 2007, 515, 8723-8727.

36 J. Datka and M. Kawałek, Collect. Czech. Chem. Commun., 1992, 57, 745-749. 